\title{
Rizobacterias promotoras del crecimiento vegetal inoculadas en dos asociaciones forrajeras: Brachiaria decumbens + Clitoria ternatea y Brahiaria hibrido cv. Mulato + Clitoria ternatea
}

\begin{abstract}
Hamilton Omar Espinales-Suárez
halomessu1419@hotmail.com

Instituto de Posgrado Maestría en Agronomía mención Producción Agrícola Sostenible

de la Universidad Técnica de Manabí Instituto Superior Tecnológico Ciudad de Valencia,

Los Ríos, Ecuador

Roger Pincay-Ganchozo Universidad Técnica de Cotopaxi, Extensión La Maná, Cotopaxi, Ecuador

Ricardo Augusto Luna-Murillo Universidad Técnica de Cotopaxi, Extensión La Maná, Cotopaxi, Ecuador
\end{abstract}

\section{RESUMEN}

En el estudio se evaluó el efecto de rizobacterias promotoras del crecimiento vegetal (RPCV) inoculadas en dos asociaciones forrajeras: Brachiaria decumbens + Clitoria ternatea y Brahiaria híbrido cv. Mulato + Clitoria ternatea. El experimento se realizó en la finca experimental "La María", de la Universidad Técnica Estatal de Quevedo en la provincia de Los Ríos-Ecuador. Utilizando el método destructivo, a los 45 y 60 días luego del trasplante y la inoculación de RCPV, en las especies vegetales de cada asociación se evaluó la longitud de raíces $(\mathrm{cm})$, peso fresco de raíces y biomasa aérea (g/planta). La composición química (proteína, grasa, ceniza y fibra) de las variedades de Brachiaria se determinó empleando los métodos propuesto por la asociación de químicos analíticos oficiales (AOAC por sus siglas en ingles). Se realizó un análisis de varianza y comparación de medias utilizando la prueba de Tukey ( $\mathrm{p}<0,05)$. El mayor peso forrajero de los pastos se obtuvo a los 60 después de la siembra. Los inoculantes $P$. fluorescens y A. vinelandii fueron los que promovieron con mayor eficacia la elongación celular y composición química de los pastos. El mayor peso forrajero de C. ternatea se obtuvo a los 60 días después de la siembra recayendo en el inoculante A. vinelandii sobre las distintas asociaciones. 
Palabras claves: Gramíneas, leguminosa, microorganismos, estados fenológicos, bromatología.

\title{
Plant growth promoting rhizobacteria inoculated into two forage associations: Brachiaria decumbens + Clitoria ternatea and Brahiaria hibrido cv. Mulato + Clitoria ternatea
}

\begin{abstract}
The study evaluated the effect of plant growth promoting rhizobacteria (PGPR) inoculated in two forage associations: Brachiaria decumbens + Clitoria ternatea and Brahiaria hybrid cv. Mulatto + Clitoria ternatea. The experiment was carried out in the experimental farm "La María", of the State Technical University of Quevedo in the province of Los Ríos-Ecuador. Using the destructive method, at 45 and 60 days after transplantation and inoculation of PGPR, in the plant species of each association, the length of roots $(\mathrm{cm})$, fresh weight of roots and aerial biomass ( $\mathrm{g} / \mathrm{plant}$ ) were evaluated. The chemical composition (protein, fat, ash and fiber) of the Brachiaria varieties was determined using the methods proposed by the association of official analytical chemists (AOAC). An analysis of variance and comparison of means were performed using the Tukey test ( $\mathrm{p}$ <.05). The highest forage weight of the pastures was obtained at 60 after sowing. The inoculants P. fluorescens and A. vinelandii were the ones that most effectively promoted cell elongation and pasture chemical composition. The highest forage weight of $\mathrm{C}$. ternatea was obtained 60 days after sowing, with the inoculant $\mathrm{A}$. vinelandii falling on the different associations.
\end{abstract}

Key words: Grass, legume, microorganisms, phenological states, bromatology.

Artículo recibido: 27 marzo 2021 Aceptado para publicación: 30 abril 2021 Correspondencia: halomessu1419@hotmail.com Conflictos de Interés: Ninguna que declarar 


\section{INTRODUCCIÓN}

La población viene creciendo y seguirá aumentado en un estado rápido así que la demanda de necesidades básicas como la alimentación debe aumentar, para satisfacer dichas necesidades se debe potencializar el sector agropecuario (Luna et al., 2017). Donde hoy en día los rendimientos agrícolas aumentan con la aplicación de fertilizantes y pesticidas sintéticos que son responsables del deterioro de los recursos naturales. En Ecuador, esta problemática ha inducido cambios bruscos de temperatura y precipitaciones afectando la producción de alimentos para el consumo local y exportación, particularmente en los trópicos ha generado disminución en la productividad de alimento forrajero para la alimentación de animales mono y poligástricos, lo que en conjunto promueve a que se incremente las cifras de ciudadanos amenazados por el hambre (Ministerio del Ambiente, 2012). Reducir los impactos ambientales negativos por fertilizantes nitrogenados, es un importante impulsador para buscar el uso más eficiente de esta crítica agronómica (Hawkesford, 2014).

Según, Yadav et al. (2019) los sistemas tradicionales de producción pecuaria basados en monocultivos de pasto tienden a agotar los recursos naturales en un proceso de degradación continua, donde la alternativa son los sistemas silvopastoriles que es un prototipo de agroforestería con un componente ganadero y se caracterizan por ser una producción más limpia que proporciona cuatro beneficios ambientales principales: el secuestro de carbono y la reducción de las emisiones de gases de efecto invernadero, la conservación de la biodiversidad, el enriquecimiento del suelo y la mejora de la calidad del aire y del agua.

Mientras tanto, Moreno et al. (2018) indicaron que la agricultura moderna enfrenta nuevos desafíos, basados en mejorar los rendimientos agrícolas impulsando el desarrollo sostenible para reducir al mínimo los impactos dañinos sobre el ambiente, donde mejorar la producción sin el uso de fertilizantes de origen sintético, ha orientado las investigaciones hacia el desarrollo de nuevas biotecnologías provocando que exista un interés creciente en los microorganismos benéficos del suelo, ya que éstos pueden promover el crecimiento de las plantas y en algunos casos evitar infecciones del tejido vegetal por patógenos, como es el caso de las rizobacterias promotoras del crecimiento vegetal (RPCV). El área agropecuaria en Ecuador es de 5,30 millones de hectáreas, donde 
el 45,10\% se encuentra ocupada por pastizales (INEC, 2019). Asu vez, Jarma et al. (2012) describieron que en los trópicos de América Latina y el Caribe se han introducido especies de gramíneas mejoradas del género Brachiaria, pasturas con resistencia a factores abióticos adversos como sequias e inundaciones, también llegan a mitigar la reducción de gases de efecto invernadero. Sin embargo, en los trópicos del Ecuador se desconoce las características agro-productivas de Brachiaria spp asociadas con leguminosas y fertilizadas con enmiendas biológicas. En este sentido, generar conocimiento sobre el buen manejo de los recursos naturales, contribuye a producir productos agropecuarios eco-eficientes.

Teniendo en cuenta a lo anterior, en el presente estudio se planteó como objetivo evaluar los efectos de rizobacterias promotoras del crecimiento vegetal inoculadas en dos asociaciones forrajeras: Brachiaria decumbens + Clitoria ternatea y Brahiaria híbrido cv. Mulato + Clitoria ternatea.

\section{MATERIALES Y MÉTODOS}

La presente investigación se llevó a cabo en la finca experimental "La María", de la Universidad Técnica Estatal de Quevedo (UTEQ), ubicada en el km 7 de la Vía Quevedo

- El Empalme, situada geográficamente a 01 06' de latitud Sur y 79²9' de longitud Oeste. A una altura de 73 metros sobre el nivel del mar. La localidad presenta un clima tropical húmedo, con precipitación de 2229,60 mm/año. Temperatura promedio anual de $24,83{ }^{\circ} \mathrm{C}$; humedad relativa $86 \%$.

En el presente estudio se evaluó las asociaciones de B. híbrido + Clitoria ternatea y $B$. decumbens + Clitoria ternatea inoculadas con Azotobacter beijerinckii; Azotobacter chroococum; Azotobacter Vinelandii; Pseudomonas fluorescens, también se llevó a cabo el protocolo sin inoculante para las dos asociaciones, donde las unidades experimentales estuvieron constituidas por las plantas sembradas en macetas de $45 \mathrm{~kg}$ al $100 \%$ de su capacidad, las cuales se les fijo fechas de cosechas que fueron a los 45 y 60 días después de la siembra (DDS). En las tres especies forrajeras se evaluó la longitud de raíces (cm), peso fresco de raíces y biomasa aérea (g/planta). Tanto a los 45 y 60 DDS se enviaron muestra del área foliar de los pastos al laboratorio de análisis químico y agropecuario (AGROLAB), Santo Domingo de los Tsáchilas, Ecuador, en donde se determinó humedad, proteína, grasa, ceniza y fibra. Empleando los métodos propuesto por la AOAC (2016). 
Para determinar el crecimiento radicular se utilizó un flexómetro en todas las edades, desde la base del tallo hasta el tope de la raíz. En la variable peso fresco de raíces se calculó considerando el peso de las unidades experimentales que fueron pesados después de haber lavadas y extraído toda la tierra. El peso de la biomasa forrajera se lo efectuó a los 45 y 60 DDS, pesando individualmente el follaje de cada especie forrajera.

Se utilizo un diseño completamente al azar con arreglo factorial: factor A (B. híbrido + Clitoria ternatea y B. decumbens + Clitoria ternatea), B (inoculantes bacterianos) y C (días después de la siembra), la unión de estos tres factores fueron los tratamientos. Se efectuaron tres replicas por tratamiento. Se empleo un análisis de varianza y comparación de medias utilizando la prueba de Tukey $(\mathrm{p}<0,05)$. Para los análisis estadísticos se utilizó el programa InfoStat (Di Rienzo et al., 2019).

\section{RESULTADOS Y DISCUSIÓN}

Entre la asociación de Clitoria ternatea con RPCV (Figura 1). El sistema de raíz de Clitoria ternatea mostró interacción simbiótica con las especies bacterianas durante los 45 y 60 días después de la siembra respectivamente. También cabe de señalar que las especies bacterianas de A. chroococum y A. beijerinckii, promovieron homogéneamente el crecimiento radicular en el intercalo de Clitoria ternatea $+B$. decumbens tanto los 45 y 60 DDS, en comparación a las demás especies bacterianas que estimularon el crecimiento radicular de manera diferenciada para los diferentes intercalo de Clitoria ternatea con Brachiaria spp, obteniendo el menor y mayor promedio a los 45 y 60 DDS respectivamente. Este fenómeno pudo deberse a que los inoculantes A. chroococum y $A$. beijerinckii presentaron un rango limitado de la colonización radicular, el cual fue inducido por la composición de la espermósfera y competencia de la rizósfera, esto atribuyo a que se interrumpa la función biológica de estas especies bacterianas, en efecto produjo que se estimule el crecimiento radicular de manera homogénea durante todo el ciclo vegetativo de Clitoria ternatea asociada con B. decumbens. Al respecto, tener una optima fito-estimluación y biofertilización sobre los cultivos por RPCV, se contempla a la interacción adecuada entre planta-microorganismo por todos los mecanismos posibles. Por otra parte, Noumavo et al. (2016) señalaron que los componentes esenciales para que las bacterias endófitas colonicen el sistema radicular, está ligado a la capacidad de las bacterias en sobrevivir después de la inoculación, esto se refiere a que las bacterias puedan resistir o tolerar el ambiente de la espermósfera para poder llegar a fijarse en la 
superficie de las primeras raíces, y así colonizar todo el sistema radicular y de esta manera llegar a tener más actividad biológica en la rizósfera. Por su parte, Moreno et al. (2018) describieron en su trabajo que ciertas bacterias endógenas toleran factores bióticos y abióticos, esto les otorga que amplíen la masa poblacional y obtengan mayor interacción con las raíces de los cultivos. En este sentido, Zamora-Olivo et al. (2013) inocularon Rhizophagus intraradices y Azospirillum brasilense en plantas de $C$. ternatea y $B$. brizantha en condiciones de trópico húmedo, suelo acrisoles, con textura franco arcillosa, $\mathrm{pH}$ ácido de 4,5 encontrando que las especies introducidas llegaron a tolerar factores bióticos y abióticos lo que provoco a estimular eficientemente las características morfobotánica de las dos especies forrajeras.

Figura 1. Longitud de raíz (cm) de Clitoria ternatea en la asociación con Brachiaria spp e inoculada con especies bacterianas del género Azotobacter y Pseudomonas, medias con una letra común no son significativamente diferentes (Tukey $p>0,05$ ).

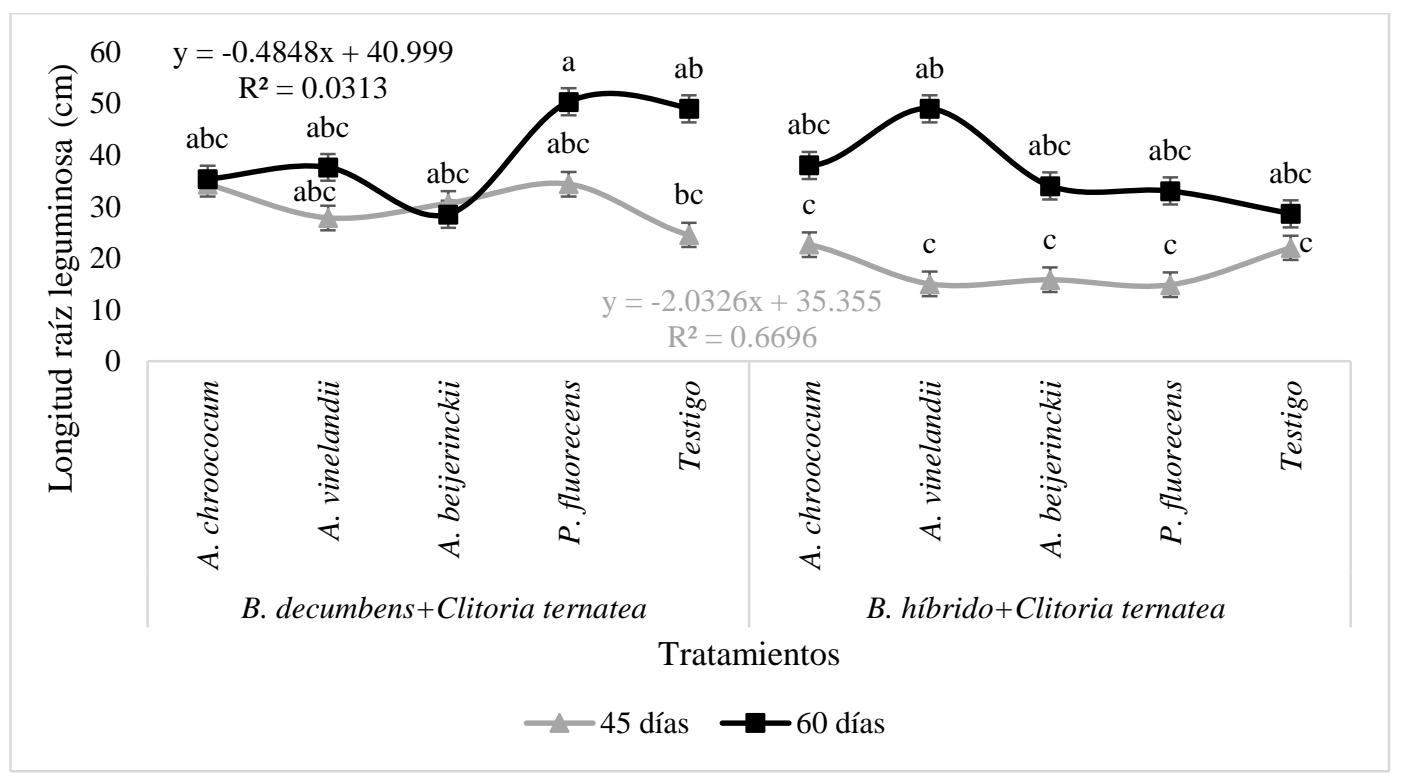

En el estudio sobre las raíces de las gramíneas forrajeras (Figura 2), el mayor crecimiento radicular se obtuvo en la asociación pasto mulato + Clitoria ternatea a los 60 DDS en el inoculante $P$. fluorecens, con $64,33 \mathrm{~cm}$ respectivamente. También se observó en la presente asociación a los 45 días DDS el mayor crecimiento sin inoculante con valores de 33,17 cm, respectivamente. De la misma forma, la asociación B. decumbens + Clitoria ternatea reflejo el mayor crecimiento sin inoculante con 47,00 cm pero a los 60 DDS, mientras que a los 45 DDS se reflejó el mejor crecimiento en el inoculante A. chroococum 
con 30,33 cm respectivamente. En los estudios realizados por, Lozano-Contreras et al. (2013) sobre el crecimiento de plántulas de Brachiaria brizantha en respuesta a la aplicación de hongos micorrizógenos y bacterias diazotróficas, estos autores no evidenciaron diferencia estadística $(\mathrm{P}<0,05)$ en el crecimiento radical por inoculante. Estos resultados concuerdan con lo reportado por Garrido et al. (2010), donde describieron que los géneros de bacterias diazotróficas pueden hacer diferir el crecimiento de las gramíneas forrajeras, debido a la diferente carga genéticas o etapas fenotípicas de las plantas.

Figura 2. Longitud raíz ( $\mathrm{cm}$ ) de Brachiaria spp en la asociación con Clitoria ternatea e inoculadas con especies bacterianas del género Azotobacter y Pseudomonas, medias con una letra común no son significativamente diferentes (Tukey $p>0,05$ ).

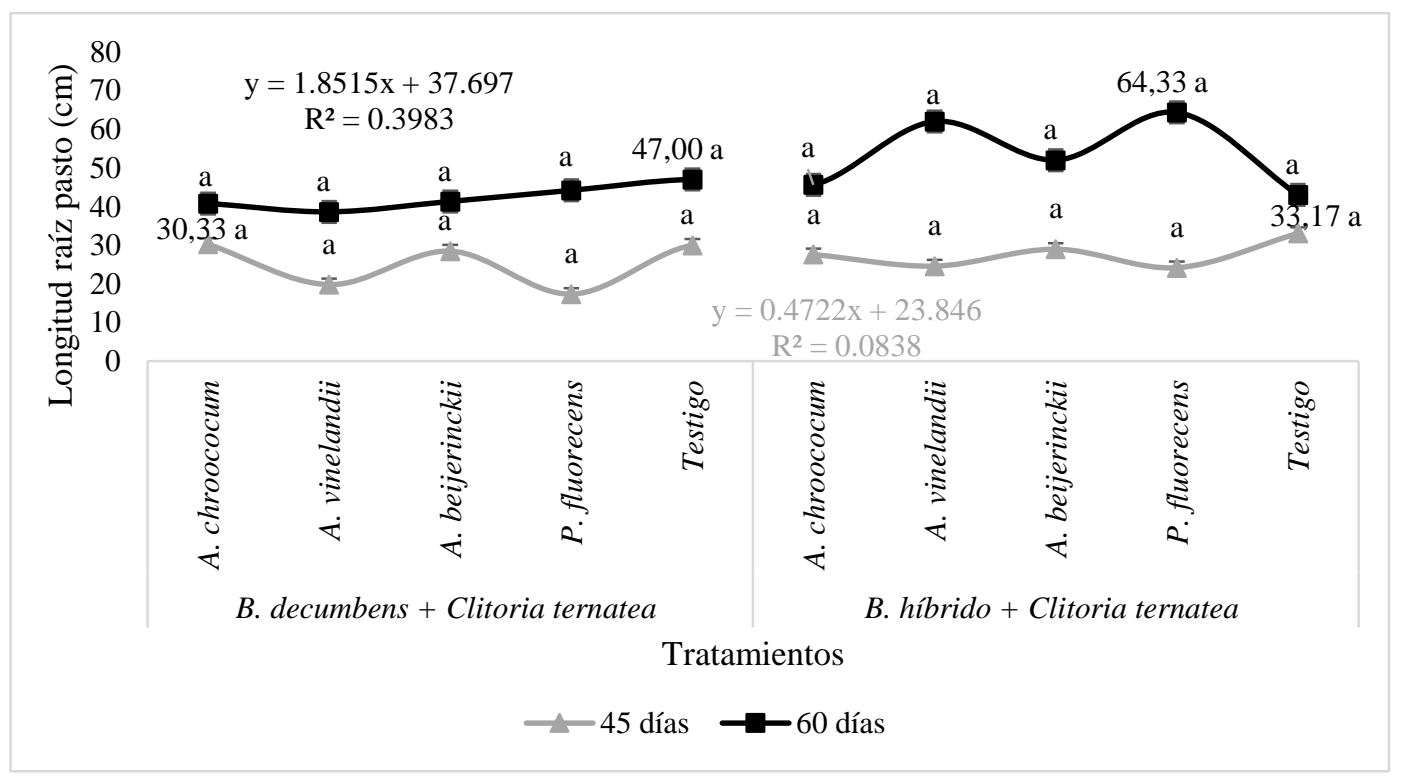

Sobre el peso de raíz leguminosa aumentado por RPCV, el mayor peso de raíz recae sobre la intercalación de $B$. decumbens $+C$. ternatea, en el inoculante A. vinelandii con 10,87 g respectivamente a los 60 DDS (Figura 3), también se observó un peso homogéneo en esta asociación de tal modo como en la longitud raíz leguminosa (figura 1), cual fue producido por el mismo inoculante $A$. beijerinckii, también siendo esta especie bacteriana producto de aumentar a los 45 DDS el mayor peso de la raíz. Respecto a la asociación $B$. híbrido + Clitoria ternatea se reflejó un peso homogéneo en el inoculante A. chroococum durante todo el ciclo vegetativo en relación que sin inoculante recae el mayor peso con 3,30 g a los 60 DDS, respectivamente. Los biofertilizantes $A$. 
beijerinckii y A. chroococum no produjeron un efecto positivo sobre el desarrollo celular del sistema raíz, esto se lo traduce a la falta de adaptabilidad de estos microorganismos sobre las condiciones edafoclimáticas en las cuales se realizó el presente estudio. López et al. (2011) realizaron estudios sobre el crecimiento de $C$. ternatea en el Valle del CautoCuba, donde evidenciaron que ciertas bacterias diazotróficas tienen problemas de adaptabilidad en el ambiente, estos autores también recalcan que la cepa bacteriana que mejor se adapte producirá un efecto positivo sobre el crecimiento de Clitoria ternatea. Por otra parte, Jamil et al. (2018) recalcaron que las condiciones ambientales influyen sobre los fitoconstituyentes de C. ternatea, tales como la sequía que conducirá a la deshidratación celular, lo que causará estrés osmótico y la eliminación del agua en las vacuolas así perdiéndose la turgencia celular.

Figura 3. Peso raíz (g/planta) de Clitoria ternatea en la asociación con Brachiaria spp e inoculadas con especies bacterianas del género Azotobacter y Pseudomonas, medias con una letra común no son significativamente diferentes (Tukey $p>0,05$ ).

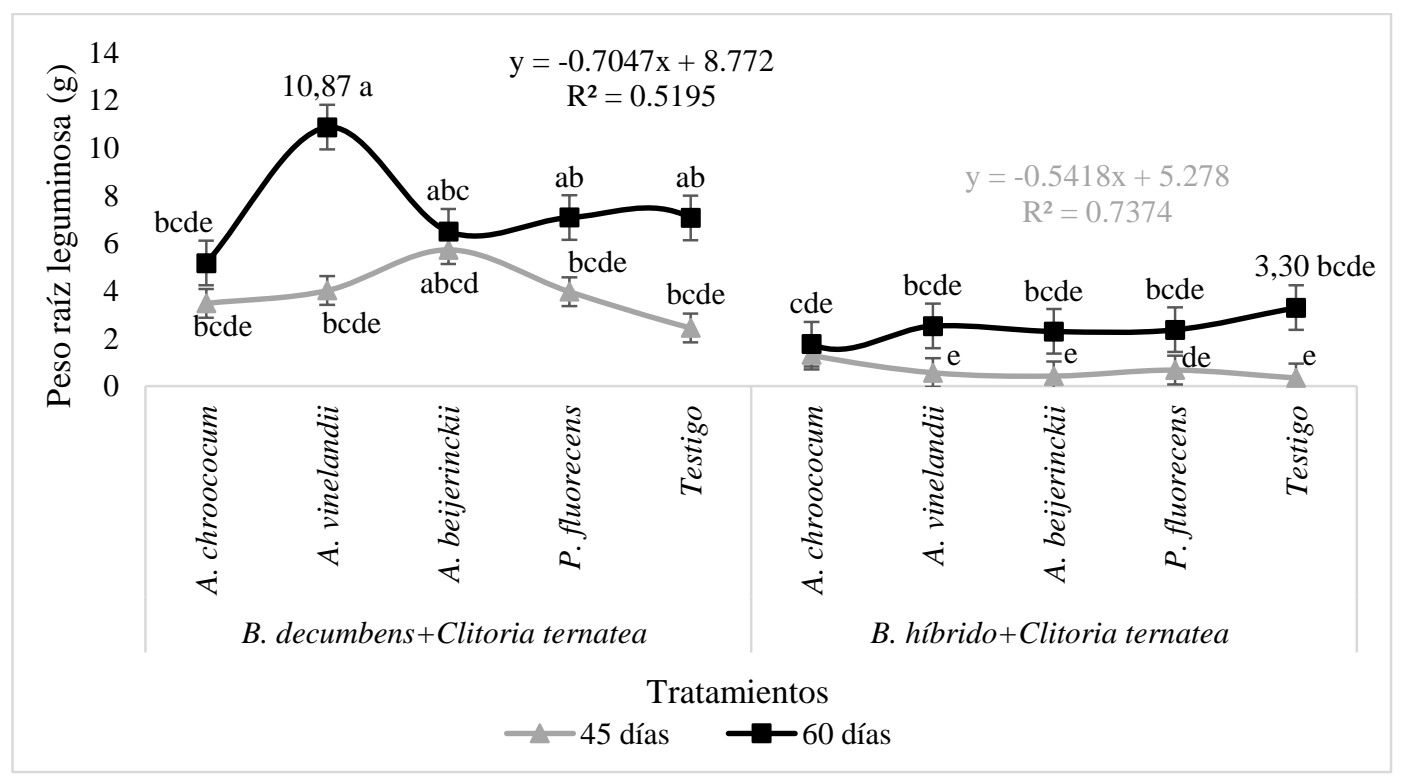

El mayor peso radicular de las gramíneas forrajeras se obtuvo a los 60 DDS (Figura 4). Respecto a las interacciones Brachiaria spp + Clitoria ternatea por inoculante, en lo que fue la asociación $B$. decumbens $+C$. ternatea en los inoculante A. beijerinckii y $A$. chroococum recae los mejores pesos de raíz con (43,88 y 102,52 cm) a los (45 y 60 DDS respectivamente). En la asociación $B$. híbrido + Clitoria ternatea, con el inoculante $A$. chroococum se presentó un peso homogéneo por todo el ciclo vegetativo del cultivo. 
Lopes et al. (2017) evaluaron los efectos de la luz y las rizobacterias en el crecimiento Brachiaria brizantha, donde obtuvieron la mayor masa radical en plantas bajo sombra y con inoculo. Según, Oliveira et al. (2018) B. decumbens interactúa con diferentes géneros de bacterias diazotróficas donde el $100 \%$ de géneros bacterianos un $70 \%$ tienen la capacidad de solubilizar fósforo, el 30\% producen celulasa y amilasa, el 60\% produce pectato liasa, el $15 \%$ produce poligalacturonasa también presenta síntesis de auxina, especialmente ácido indolacético, las cuales promueven el crecimiento de raíces secundarias, terciarias, cuaternarias por tanto las plantas absorberán mayor cantidad de agua y nutrientes (Li et al., 2016).

Figura 4. Peso radicular (g/planta) de Brachiaria spp en la asociación con Clitoria ternatea e inoculada con rizobacterias del género Azotobacter y Pseudomonas, medias con una letra común no son significativamente diferentes (Tukey $p>0,05$ ).

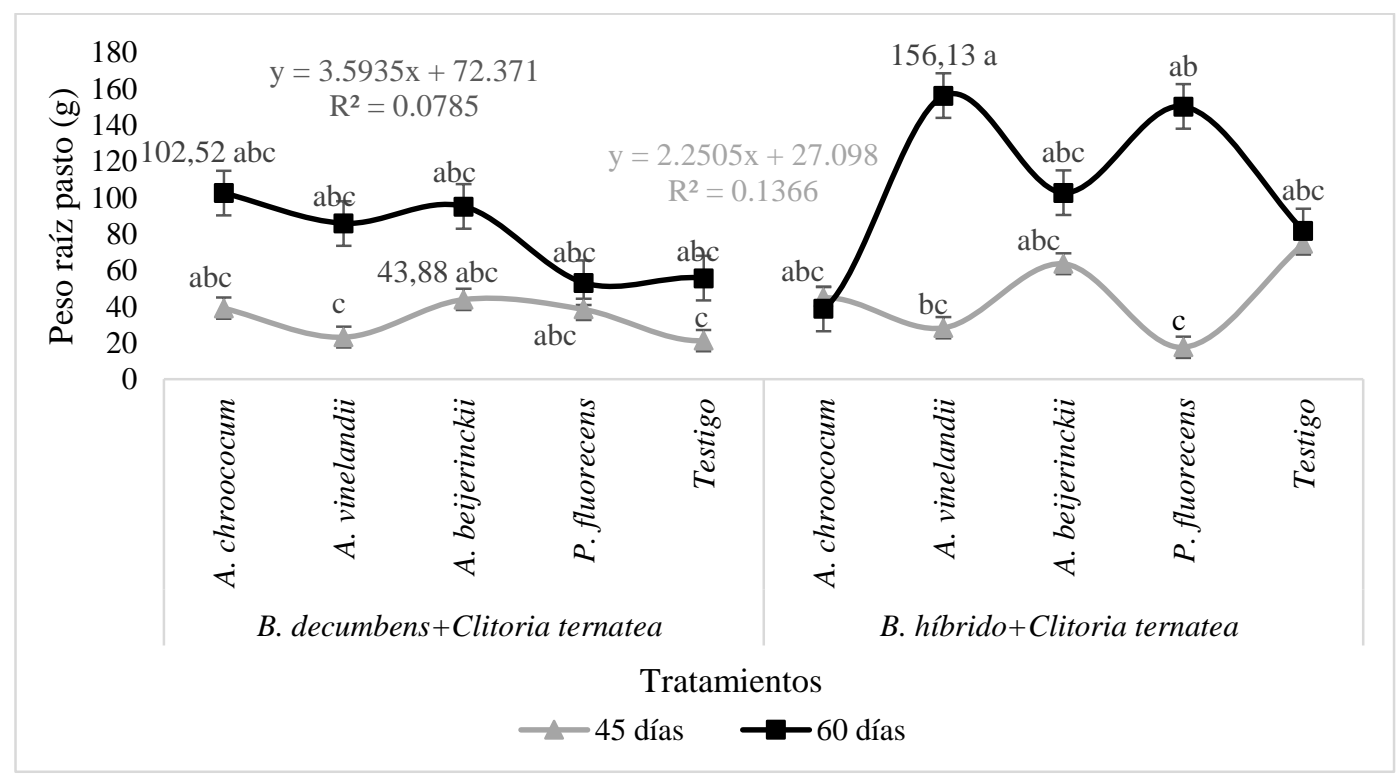

El mayor peso forrajero de C. ternatea se obtuvo a los 60 DDS recayendo en el inoculante A. vinelandii sobre las distintas asociaciones (Figura 5). Romero et al. (2013) evaluaron el rendimiento y calidad de la Clitoria ternatea en relación con la edad, donde observaron de igual forma el mayor contenido de biomasa a los 60 días de rebrote. Resultados que concuerdan con lo descrito por Ramírez et al. (2010), quienes describen que la tasa de producción de hojas puede variar en cualquier etapa fenotípica, en efecto esto produce variación sobre la biomasa foliar. Según, el coeficiente de correlación existió una estrecha 
relación entre la biomasa forrajera y peso radical por inoculante, tanto para la asociación de B. decumbens + Clitoria ternatea y B. híbrido + Clitoria ternatea.

Figura 5. Biomasa aérea (g/planta) de Clitoria ternatea con la asociación de Brachiaria decumbens y Brachiaria hibrido Mulato e inoculada con rizobacterias del género Azotobacter y Pseudomonas, medias con una letra común no son significativamente diferentes (Tukey $p>0,05)$.

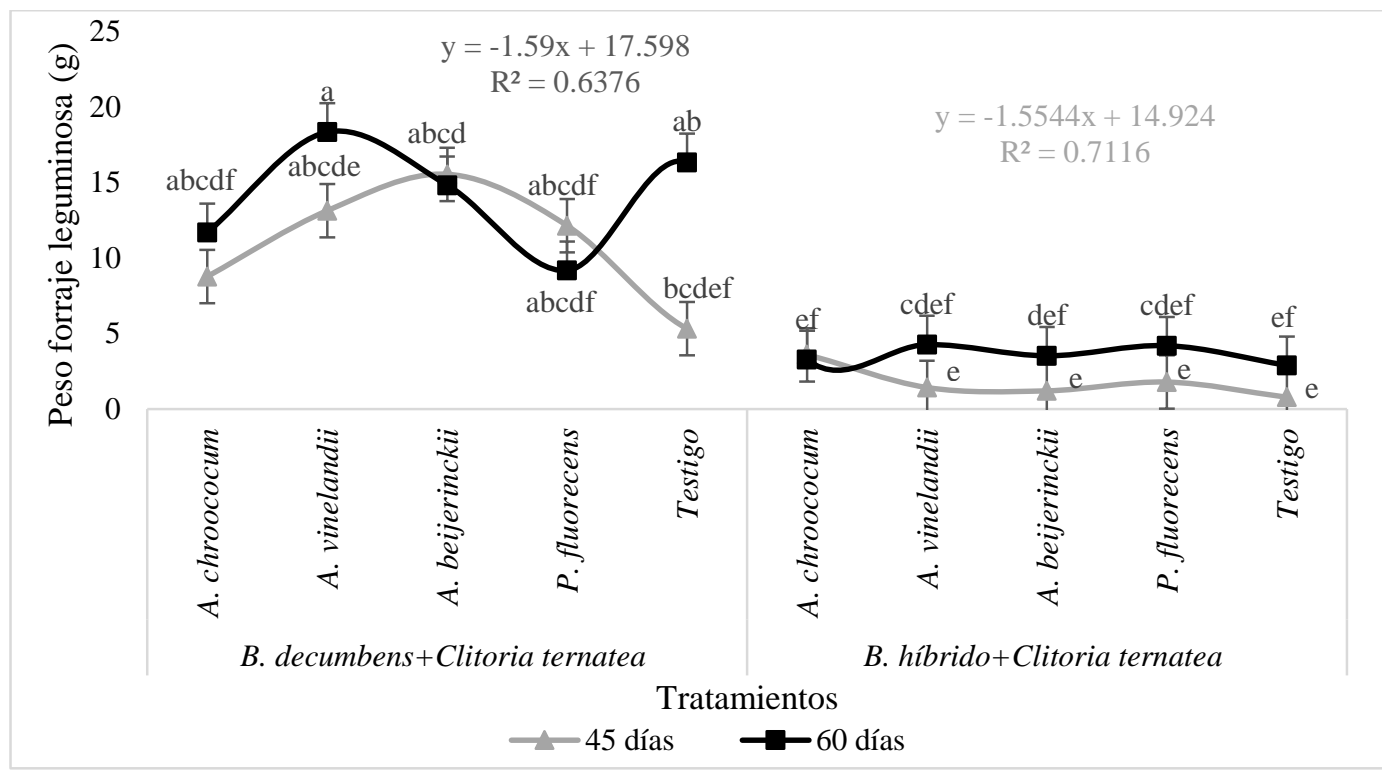

El mayor peso forrajero de los pastos se obtuvo a los 60 DDS (Figura 6), el cual recae en los inoculantes de A. chroococum y $P$. fluorescens con valores de 81,10 y 165,63 g respectivamente para $B$. decumbens y $B$. híbrido, también se visualizó que a los 45 DDS en el inoculante $P$. fluorescens se obtuvo el mayor peso forrajero, tanto para las dos asociaciones. Mientras tanto, Lopes et al. (2018) evaluaron el efecto de Pseudomonas fluorescens y Burkholderia pyrrocinia sobre el pasto Brachiaria brizantha, de igual manera obtuvieron la mayor biomasa forrajera en Pseudomonas fluorescens la cual reflejo $227 \%$ en relación a Burkholderia pyrrocinia que obtuvo 95\%. En forma general se observó que la parte área obtuvo una gran analogía con los sistemas radiculares. Sin embargo, Maleko et al. (2019) indican que las especies forrajeras concretamente las de la familia gramínea manifiestan diferentes cambios morfo-botánicos, específicamente estas no presentan rasgos uniformes si no variados entre la parte aérea y raíces. Por otra parte, 
Martín et al. (2018) evidenciaron variabilidad en la morfo-anatomía de Brachiaria spp, debido a factores bióticos y abióticos.

Figura 6. Biomasa aérea (g/planta) de Brachiaria spp asociadas con Clitoria ternatea e inoculadas con rizobacterias del género Azotobacter y Pseudomonas, medias con una letra común no son significativamente diferentes (Tukey $p>0,05$ ).

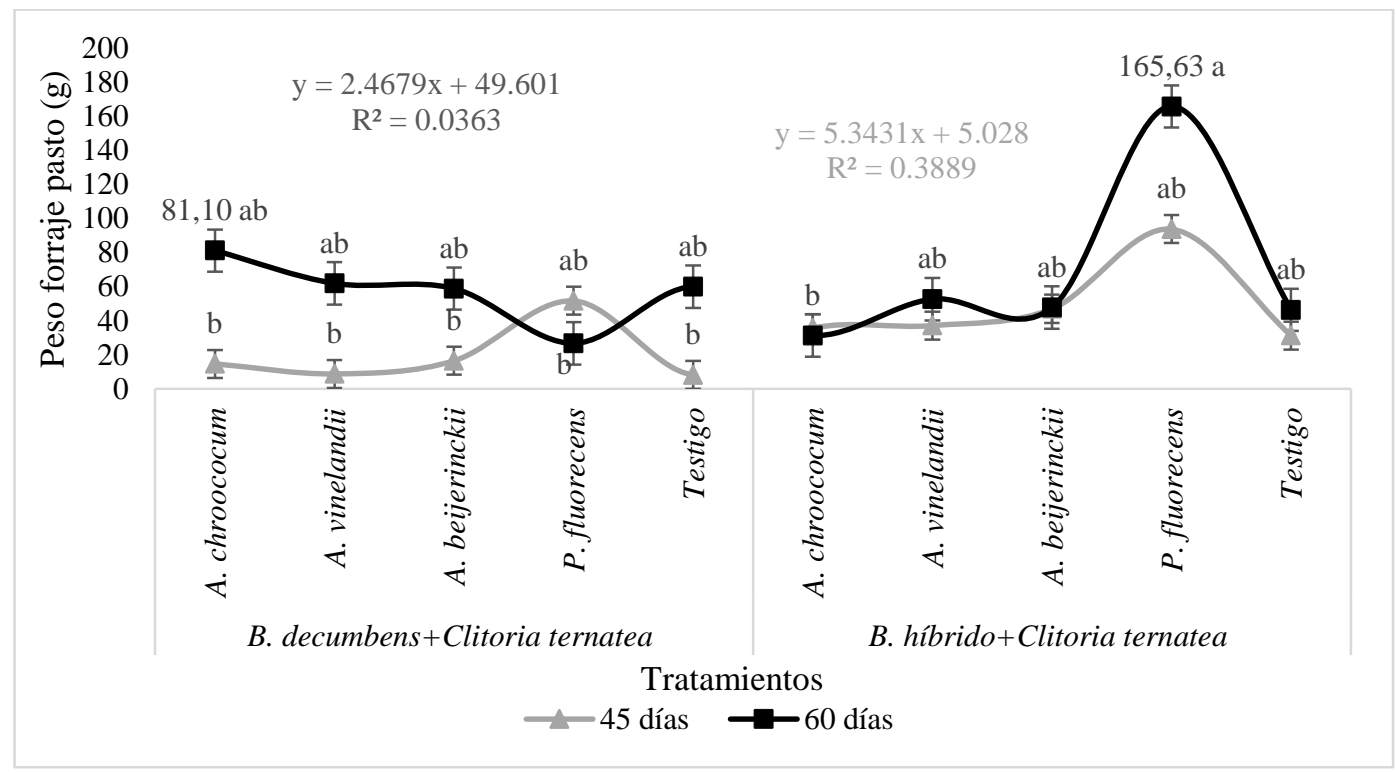

En la tabla 1 se observa la composición química de las pasturas. El mayor porcentaje de materia seca se obtuvo a los 45 DDS en el pasto mulato con el inoculante $A$. Chroococum reflejando valores de $66,71 \%$ respectivamente, la misma gramínea produjo la mayor cantidad de proteína y fibra con $(15,70$ y $43,20 \%)$ en el inoculante A. beijerinckii a los (45 y 60 DDS respectivamente). El pasto mulato de igual modo sobresale en el contenido de ceniza con $12,33 \%$ influenciado por $P$. fluorescens a los 45 DDS respectivamente. En los estudios realizado por, Balseca et al. (2015) encontraron el mayor contenido de PC en B. decumbens y el mayor valor de FC en B. hibrido cv. Mulato II con ( 9,1 y 45,4 \% respectivamente). Canchila et al. (2009) evaluaron en monocultivo la composición bromatológica de 24 accesiones de Brachiaria spp, donde reportaron porcentajes de cenizas con (5,5 y 9,0\%) en (B. humidicola CIAT-26427 y B. híbrido CIAT-1873 respectivamente), contenido de materia seca en un rango de (23,4 a 25,7\%), los valores más bajos recayeron en (B. ruziziensis CIAT-26180 y B. brizantha CIAT-16212) y los más altos sobre (B. brizantha CIAT-16467 y CIAT-16488), en proteína encontraron valores que fluctuaron de (5,8 a 7,5\%) los menores valores se reflejaron en $B$. humidicola CIAT 26159 y los mayores se obtuvieron en B. brizantha CIAT 26124 y CIAT 6387. 
Resultados que son diferentes a los de nuestros estudios. Estos autores también refieren que el contenido celular está relacionado con la variabilidad de climas y edad de corte de los pastos, manejo agronómico y actividad biológica en la rizósfera donde especies de microorganismo benéfico son adherentes a cada especie forrajera, esto conlleva a que la planta tenga variabilidad en cada reacción bioquímica que realice.

Tabla 1. Composición química de Brachiaria spp en la asociación con Clitoria ternatea e inoculada con rizobacterias del género Azotobacter y Pseudomonas.

\begin{tabular}{|c|c|c|c|c|c|c|}
\hline Pasto & Inoculante & Edad & $\begin{array}{l}\text { MS } \\
(\%)\end{array}$ & $\begin{array}{c}\text { Proteína } \\
(\%)\end{array}$ & $\begin{array}{c}\text { Ceniza } \\
(\%)\end{array}$ & $\begin{array}{c}\text { Fibra } \\
(\%)\end{array}$ \\
\hline \multirow{10}{*}{$\begin{array}{l}\text { Brachiaria } \\
\text { decumbens }\end{array}$} & \multirow{2}{*}{ A. Chroococum } & 45 & 64,81 & 7,23 & 6,63 & 36,10 \\
\hline & & 60 & 36,64 & 14,37 & 8,81 & 37,40 \\
\hline & \multirow[t]{2}{*}{ A. Vinelandii } & 45 & 62,87 & 10,00 & 7,28 & 30,30 \\
\hline & & 60 & 28,78 & 9,37 & 7,62 & 33,30 \\
\hline & \multirow[t]{2}{*}{ A. beijerinckii } & 45 & 58,56 & 12,50 & 6,94 & 32,90 \\
\hline & & 60 & 36,90 & 10,00 & 9,09 & 40,10 \\
\hline & \multirow[t]{2}{*}{ P. fluorescens } & 45 & 54,73 & 13,20 & 6,63 & 32,30 \\
\hline & & 60 & 38,05 & 8,12 & 10,07 & 32,40 \\
\hline & \multirow[t]{2}{*}{ testigo } & 45 & 65,71 & 4,85 & 8,96 & 26,30 \\
\hline & & 60 & 40,14 & 8,12 & 7,30 & 30,90 \\
\hline \multirow{10}{*}{$\begin{array}{l}\text { Brachiaria } \\
\text { híbrido }\end{array}$} & \multirow[t]{2}{*}{ A. Chroococum } & 45 & 66,71 & 5,70 & 7,06 & 40,50 \\
\hline & & 60 & 53,04 & 4,37 & 9,53 & 42,20 \\
\hline & \multirow[t]{2}{*}{ A. vinelandii } & 45 & 53,28 & 5,70 & 10,00 & 34,80 \\
\hline & & 60 & 52,01 & 5,62 & 9,23 & 42,10 \\
\hline & \multirow[t]{2}{*}{ A. beijerinckii } & 45 & 50,13 & 15,70 & 10,11 & 35,10 \\
\hline & & 60 & 58,85 & 3,75 & 6,89 & 43,20 \\
\hline & \multirow[t]{2}{*}{ P. fluorescens } & 45 & 36,54 & 5,00 & 12,33 & 27,40 \\
\hline & & 60 & 42,97 & 7,50 & 9,20 & 41,60 \\
\hline & \multirow{2}{*}{ testigo } & 45 & 51,73 & 5,70 & 8,99 & 36,10 \\
\hline & & 60 & 47,77 & 6,87 & 8,42 & 42,10 \\
\hline
\end{tabular}

\section{CONCLUSIÓN}

Las especies bacterianas estudiadas presentaron selectividad de hospedero. La mayor biomasa aérea de $B$. decumbens y $B$. híbrdido en asociación con $C$. ternatea e inoculadas con rizobacterias se obtuvo a los 60 DDS. Los inoculantes $P$. fluorescens y $A$. vinelandii fueron los que promovieron con mayor eficacia la elongación celular y composición química de los pastos. El mayor peso de forraje de C. ternatea se obtuvo a los 60 días después de la siembra recayendo en el inoculante $A$. vinelandii sobre las distintas asociaciones. 


\section{REFERENCIAS}

Association of Official Analytical Chemists (AOAC). 2016. Official methods of analysis of AOAC International. 20th Ed. Rockville, MD, USA. 771p.

Balseca, D.; Cienfuegos, E.; López, H.; Guevara, H.; y Martínez, J. 2015. Nutritional value of Brachiaria and forage legumes in the humid tropics of Ecuador. Ciencia e Investigación Agraria, 42(1): 57-63.

Canchila, E.R.; Soca, M.; Ojeda, F; Machado, R. 2009. Evaluación de la composición bromatológica de 24 accesiones de Brachiaria spp. Pastos y Forrajes, 32(4): 1-9.

Di Rienzo J.A.; Casanoves F.; Balzarini M.; Gonzalez L.; Tablada M.; Robledo C. InfoStat versión 2019. Centro de Transferencia InfoStat. FCA. Universidad Nacional de Córdoba. Argentina.

Garrido, M.; Cardenas, D.; Bonilla, R.; Baldani, V. 2010. Efecto de los factores edafoclimáticos y la especie de pasto en la diversidad de bacterias diazotróficas. Pastos y Forrajes, 33(4):1-11.

Instituto Nacional de Estadísticas y Censo (INEC). 2019. Encuesta de superficie y producción agropecuaria continua. Boletín técnico. $13 \mathrm{p}$.

Jamil, N.; Mohd, M. Z.; Mohd, N.; Pa'ee, F. 2018. Influences of Environmental Conditions to Phytoconstituents in Clitoria ternatea (Butterfly Pea Flower)-A Review. Journal of Science and Technology, 10(2):208-228.

Jarma, A.; Maza, L.; Pineda, A.; Hernández, J. 2012. Aspectos fisiológicos y bromatológicos de Brachiaria humidicola.CES Medicina Veterinaria $y$ Zootecnia, 7 (1): 88-99.

Li, X.; Zeng, R.; Liao, H. 2016. Improving crop nutrient efficiency through root architecture modifications. J Integr Plant Biol, 58: 193-202.

Lopes, M.; Dias-Filho, M.; Castro, T.; Filippi, M.; Silva, G. 2018. Effect of Pseudomonas fluorescens and Burkholderia pyrrocinia on the GrowthImprovement and Physiological Responses in Brachiaria brizantha. American Journal of Plant Sciences, 9: 250-265.

Lopes, M.; Dias-Filho, M.; Castro, T.; Silva, G. 2017. Light and plant growth-promoting rhizobacteria effects on Brachiaria brizantha growth and phenotypic plasticity to shade. Grass Forage Sci,00:1-7. 
López Sáncheza, R.; Samsonb, R.; Vandammec, P.; Eichler-Löbermannd, B.; Gómez Padilla E. 2011. Respuesta de combinaciones Rhizobium-Clitoria ternatea en condiciones de estrés salino en el Valle del Cauto en Cuba. Rev Mex Cienc Pecu, 2(2):199-207.

Lozano-Contreras, M.; Rivas-Pantoja, F.; Castillo-Huchim, J. 2013. Crecimiento de plántulas de Brachiaria brizantha en respuesta a la aplicación de hongos micorrizógenos y bacterias diazotróficas. Pastos y Forrajes, 36(2): 227-232.

Luna, S.; Perales, A.; Lastiri, A. 2017. Calentamiento global, población, alimentación y sustentabilidad: límites en el contexto económico y social del sector agropecuario en México. Crecer Empresarial: Journal of Management and Development, $\mathrm{n}^{\circ}$ especial (1):1-12.

Hawkesford, M. J. 2014. Reducing the reliance on nitrogen fertilizer for wheat production Journal of Cereal Science, 59 (3): 276-283.

Martín, R.; Dell’Amico, J.; Cañizares, P. 2018. Respuesta del pasto cayman (Brachiaria híbrido cv. Ciat Bro2/1752) al déficit hídrico. Cultivos Tropicales, 39(1): 113118.

Maleko, D.; Mwilawa, A.; Msalyac, G.; Pasape, D.; Mtei K. 2019. Forage growth, yield and nutritional characteristics of four varieties of napier grass (Pennisetum purpureum Schumach) in the west Usambara highlands, Tanzania. Scientific African, 6: 1-9.

Ministerio del Ambiente. 2012. Estrategia Nacional de Cambio Climático del Ecuador 2012-2025.

Moreno, A.; García, V.; Reyes, J.; Vásquez, J.; Cano, P. 2018. Rizobacterias promotoras del crecimiento vegetal: una alternativa de biofertilización para la agricultura sustentable. Revista Colombiana de Biotecnología, 20(1):68-83.

Noumavo, P. A.; Agbodjato, N. A.; Baba-Moussa, F.; Adjanohoun, A.; Baba-Moussa, L. 2016. Plant growth promoting rhizobacteria: Beneficial effects for healthy and sustainable agriculture. Afr. J. Biotechnol, 15(27):1452-1463.

Oliveira, J. T.; Silva, G. T.; da Silva, W. P.; Fernandes, E.; dos Santos, I. B. Moreira, D. R.; Quecine, M.; Kuklinsky-Sobral, J.; Freire, F. J. 2018. Diazotrophic bacteria isolated from Brachiaria spp: genetic and physiological diversity. Ciencia $e$ investigación agraria, 45(3): 277-289. 
Ramírez, J. L.; Herrera, R. S.; Leonard, I.; Verdecia, D.; Álvarez, Y. 2010. Rendimiento de materia seca y calidad nutritiva del pasto Brachiaria brizantha x Brachiaria ruziziensis cv. Mulato en el Valle del Cauto, Cuba. Ciencia Agrícola, 44 (1): 6572.

Romero, N.; Leonard, I.; Ramírez, J.; Córdova, A. 2013. Rendimiento y calidad de la Clitoria ternatea en un suelo arcilloso del estado Falcón, Venezuela. Revista Electrónica de Veterinaria, 14 (10):1-10.

Yadav, A.; Gendley, M.K.; Sahu, J.; Kumar, P.; Chandraker K.; Dubey, A. 2019. Silvopastoral system: A prototype of livestock agroforestry. The Pharma Innovation Journal, 8(2): 76-82.

Zamora-Olivo, M.; Aguirre-Medina, J.; Cano-García, M.; Martínez-Tinajero, J. 2013. Productividad de Brachiaria brizantha (Hochst. ex A. Rich) y Clitoria ternatea con biofertilizantes. AGROProductividad, 6(6): 23-30. 